Marine Illumination Device

Federal Manufacturing \& Technologies

L. J. Cain

KCP-613-6350

Published August 2000

Final Report/CRADA Accomplishments Summary

CRADA Number 98KCP1062

Approved for public release; distribution is unlimited.

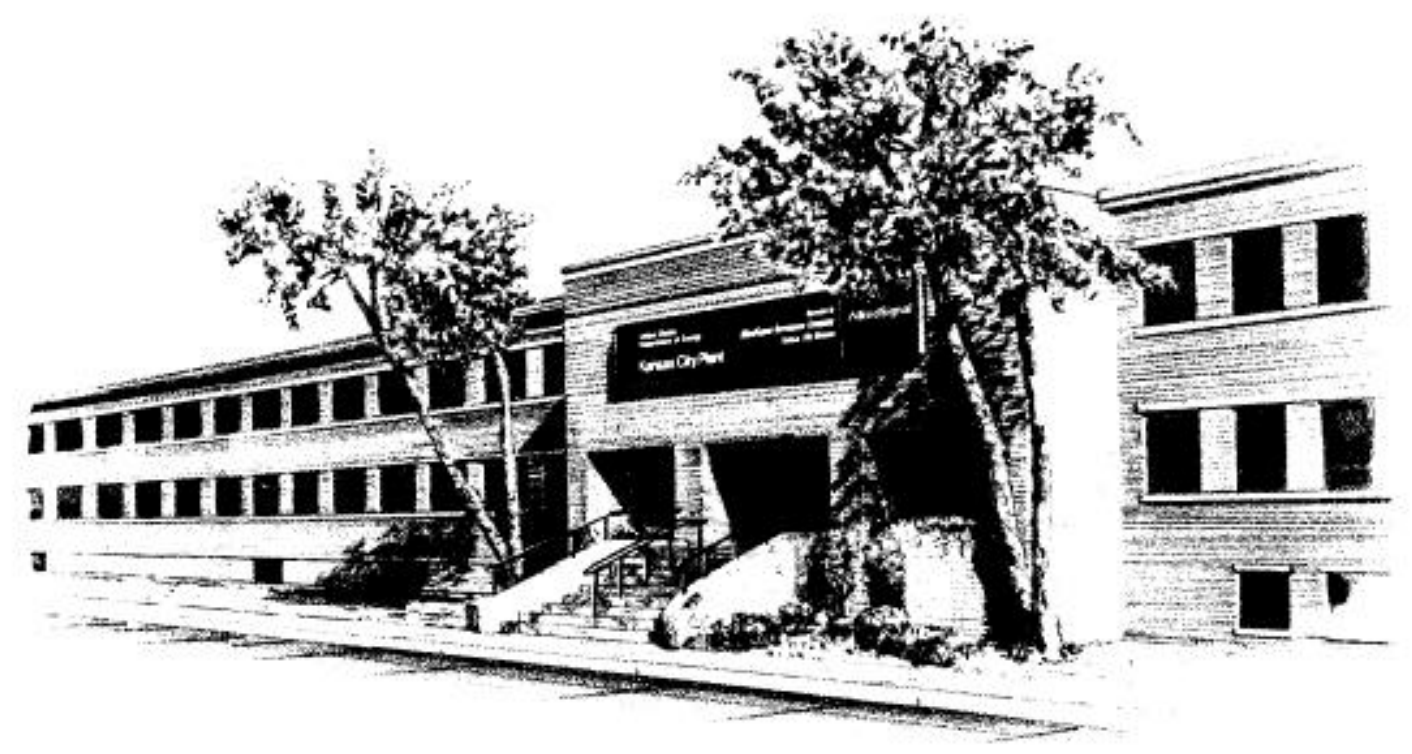

Prepared Under Contract Number DE-ACO4-76-DP00613 for the

United States Department of Energy

\title{
DISCLAIMER
}

This report was prepared as an account of work sponsored by an agency of the United States Government. Neither the United States Government nor any agency thereof, nor any of their employees, makes any warranty, express or implied, or assumes any legal liability or responsibility for the accuracy, completeness, or usefulness of any information, apparatus, product, or process disclosed, or represents 
that its use would not infringe privately owned rights. Reference herein to any specific commercial product, process, or service by trade names, trademark, manufacturer, or otherwise, does not necessarily constitute or imply its endorsement, recommendation, or favoring by the United States Government or any agency thereof. The views and opinions of authors expressed herein do not necessarily state or reflect those of the United States Government or any agency thereof.

Printed in the United States of America.

This report has been reproduced from the best available copy.

Available to DOE and DOE contractors from the Office of Scientific and Technical Information, P. O. Box 62, Oak Ridge, Tennessee 37831; prices available from (865) 576-8401, FTS 626-8401.

Available to the public from the National Technical Information Service, U. S. Department of Commerce, 5285 Port Royal Rd., Springfield, Virginia 22161, (703) 487-4650.

Honeywell

Federal Manufacturing $\&$ Technologies

P. O. Box 419159

A prime contractor with the United States

Kansas City, Missouri

Department of Energy under Contract Number

64141-6159

DE-ACO4-76-DP00613.

Honeywell

KCP-613-6350

Distribution Category UC-706

Approved for public release; distribution is unlimited. 


\title{
L. J. Cain
}

Published August 2000

Final Report/Project Accomplishments Summary

CRADA Number 98KCP1062

\section{Marine Illumination Device}

\author{
Project Accomplishments Summary
}

CRADA Number 98KCP1062

Date: May 22, 2000

Revision: 0

\section{A. Parties}

The project is a relationship between

Honeywell FM\&T

$2000 \mathrm{E} 95^{\text {th }}$ Street

PO Box 419159

Kansas City, MO 64141-6159
Innovative Lighting

PO Box 494

813 N. Roan St.

Algona, Iowa 50511-0494

\section{B. Background}

Innovative Lighting Corporation (ILC) is a small business that has patented a remote-controlled, motorized telescoping marine light called PowerLight. PowerLight's telescoping mast can extend up to five feet and is intended for use as a stern navigation light. The invention is space saving, convenient, and replaces the need for a bulky stick light.

PowerLight was introduced into the recreational boat market as an option on a popular, name-brand powerboat. Early into the market introduction, ILC began experiencing customer returns of the PowerLight due to a variety of catastrophic and intermittent electrical failures primarily due to the harsh, wet environment. ILC tried using several 
electrical engineering contractors to identify the cause of failure. The end result of their efforts did not succeed in developing a high-quality, failure-free product. Product returns were still plaguing this small business of fewer than five employees.

Product returns were affected by the seasonality of the powerboat industry. Defective PowerLights were returned to distributors, sometimes held until the end of the boating season, and then returned to the manufacturer. Less than prompt identification of the failure mode made it difficult to isolate the root cause of the problem. Like most niche markets, the powerboat market is tightly networked among the boat manufacturers. Continual product returns will generate a reputation of an unreliable product and a low quality supplier. At the start of the project the PowerLight was the only product being sold by ILC.

ILC originally contacted Federal Manufacturing \& Technologies (FM\&T) to request engineering assistance through the DOE's Small Business Initiative. Engineering assistance to test the PowerLight indicated potential design flaws that were apparent during power surges. The company incorporated several suggestions into their design to eliminate the failures. ILC felt the suggestions had a positive impact on the number of failures.

\section{Description}

The purpose of this Cooperative Research and Development Agreement was to perform an extensive design review and design a new microcontroller-based motor controller to operate the telescoping light. The new design tasked FM\&T to utilize off-the-shelf components instead of military-specified components with higher reliability. The improved motor controller design looked at significantly reducing the overall component cost. FM\&T brought specific strengths and capabilities to this project including custom circuit design, special testing, and troubleshooting expertise.

In addition, ILC redesigned the housing and evaluated options to lower other component costs. ILC recognized the need for a redesign to eliminate other inefficiencies in the product's design. However, significant added costs to improve the product's reliability would make it difficult to attract the interest of boat manufacturers.

The final objective was for FM\&T to provide ILC with a tester to functionally test their PowerLight controller circuits before they were assembled onto the light and shipped to their customers. This would further reduce the incidence of customers receiving defective product from ILC.

ILC redesigned the light housing and provided CAD designs for solid modeling. FM\&T performed finite element analysis (FEA) to determine critical stress areas and performed a mechanical design review to determine if other improvements in the product design or manufacturability could be made. During this process it was found that the housing and mounting insulator, the device that pushes the mast up and down, would not coil properly into the housing. A clear housing was created, and the mast operation was videotaped to observe the problem in slow motion, which illustrated the cause of the trouble. Subsequently, a new housing was designed which allows the housing and mounting insulator to coil within the hub without binding. 
FM\&T's Test Equipment Engineering and ILC also initiated a microcontroller development program to successfully design, prototype, test, and qualify a fully functional motor controller to operate the telescoping light. The new design focused on off-the-shelf commercial components that were cost-effective and met the requirements to eliminate noise spikes and reduce power interruptions and low voltage problems.

The motor controller was thoroughly tested to determine whether the circuit was fully capable of withstanding voltage spikes, reverse polarity, and normal adverse operating conditions. Alternate designs were investigated, and the circuit design with the discrete motor driver and a resettable circuit protector was found to suit the application best.

The other objective was to lower the cost of the circuit. A cheaper microcontroller was researched since it was the most expensive component in the circuit. A die-shrink version of the microcontroller was found manufactured by the same company. This was the ideal choice since the only change it would bring about was a cost savings of $\$ 1.11$ per chip. Another change involved replacing the [ watt resistors with $1 / 4$ watt versions. Even though the circuit does not require the larger $1 / 4$ watt resistors, they are more available and therefore cheaper. This further reduced the circuit price by $4 \notin$ each.

The last change that was implemented was one of seeking out distributors that offer prices lower than those ILC was already using for the same parts. The largest savings from this effort was to eliminate the microcontroller programming charge of $\$ 4$ per chip. If the microcontroller were purchased in large enough quantities, the distributor would program it at no charge.

Changing the circuit to surface mount components and adding a header connector for testing were also explored. The surface mount option was found to be more costly and the header connector was dropped in favor of on-board test pads for spring-loaded test pins to facilitate testing. At completion the circuit cost was reduced by $39 \%$. This represents a surprising reduction given the small number of components in the circuit.

Toward the end of the project FM\&T designed and fabricated a functional tester for product acceptance. It is a lightweight, portable unit, approximately the size of a cosmetic case that provides a GO / NO GO test capability for the motor controller prior to shipping. The tester was built entirely from commonly available parts so that replacement components could be easily obtained and thorough documentation was provided to facilitate repairs and troubleshooting.

\section{Expected Economic Impact}

ILC benefited by being able to eliminate problems through enhanced testing and engineering capabilities that it otherwise did not have access to. The redesign of the PowerLight technology provided ILC with an attractive, technologically advanced product with which to solidify its position within the powerboat industry and grow its business. The industry will benefit because a dependable PowerLight will enhance the safety of nighttime boating. As this product is put into use, it will directly reduce the citations issued by the DNR, as nearly one fourth of such citations currently are for improper or non-existent navigation lighting. And also, taxpayers will benefit through the generation of new employment and more jobs in a rural area. At the close of this project ILC has 
expanded their product line to include the manufacture of accent lighting for home decks and side marker lights for truck trailers. As its reliability increases, the PowerLight is gradually becoming a product noted as a differentiating sales feature rather than just another option.

\section{E. Benefits to DOE}

This project maintained and enhanced the readiness, analysis, and design capability necessary to support defense program components and assemblies. Specifically, the low-cost microcontroller section of the circuit can be used for tester sub-functions during testing of the electronic assemblies for Trajectory Sensing Signal Generators (TSSGs). This project also provided a useful means of familiarizing FM\&T with the selection and capabilities of some groups of commercial circuit components that have not been utilized in the past. This, in turn, will allow FM\&T to better implement new components in the development of custom tester stimulus and measurement circuits as well as expose FM\&T to new circuit design schemes.

\section{F. Industry Area}

The industry area benefiting from this project is marine safety.

\section{G. Project Status}

The project was completed with an extension applied to the schedule.

\section{H. Point of Contact for Project Information}

Ken Bauer

US Department of Energy

Kansas City Area Office

PO Box 410202

Kansas City, MO 64141-0202

Telephone: (816) 997-3917

Fax: (816) 997-5059

\author{
Lyle J. Cain
}

Honeywell FM\&T

PO Box 419159

Kansas City, MO 64141-6159

Telephone: (816) 997-5339

Fax: (816) 997-7169

I. Company Size and Point of Contact 
Innovative Lighting has nine employees and annual sales of \$1 Million. The President, Jerry Handsaker, was responsible for their portion of the project and can provide any necessary feedback. His phone number is (515) 295-9391 and fax number is (515) 295-6161.

\section{J. Project Examples}

Digital photos of the tester were taken prior to delivery to ILC. Copies can be provided upon request.

\section{K. Technology Commercialization}

This section did not apply to this project. All technologies were already commercialized.

L. Release of Information

I have reviewed the attached Project Accomplishment Summary prepared by Honeywell FM\&T and agree that the information about our CRADA may be released for external distribution.

Original signed by 8-17-00

Name: Jerrold L. Handsaker

Date:

Organization: Innovative Lighting, Inc.

Title: President 